\title{
RANCANG BANGUN SISTEM INFORMASI PENJUALAN TIKET KAPAL EXPRESS BAHARI 1C GRESIK - BAWEAN BERBASIS WEB
}

\author{
M. Farid Husni Mubarok ${ }^{1}$, Ariadi Retno Tri Hayati Ririd ${ }^{2}$, Nurudin Santoso ${ }^{3}$ \\ ${ }^{1}$ Program Studi Teknik Informatika, ${ }^{2}$ Jurusan Teknik Elektro, ${ }^{3}$ Politeknik Negeri Malang \\ 19mf.husny@gmail.com, ${ }^{2}$ faniri4education@yahoo.com, ${ }^{3}$ nurudin.santoso@gmail.com
}

\begin{abstract}
Abstrak
Dengan kemudahan adanya internet penyedia jasa khususnya pada PT Pelayaran akan dimudahkan dalam menjalankan bisnisnya, karena dalam penyampaian informasi dan pengolahan data penjualan dapat dicapai dengan membangun sebuah web. Web saat ini adalah sarana terbaik sebagai sarana informasi dan promosi. Dengan adanya web ini diharapkan dapat mengurangi antrian saat calon penumpang membeli tiket kapal diloket. Karena proses penjualan tiket yang masih dilakukan secara manual, sehingga penyedia tiket akan kualahan dalam melayani calon penumpang dalam waktu bersamaan saat ramai-ramainya khususnya pada musim mudik. Maka dibangunlah sebuah sistem informasi penjualan tiket untuk meningkatkan perbaikan pelayanan penjualan tiket dan untuk memudahkan calon penumpang membeli tiket. Sistem Informasi ini dibangun menggunakan bahasa pemrograman PHP dan HTML serta menggunakan basis data Mysql. Dengan fitur pengaturan jadwal keberangkatan, mengelola booking, memperbaharui informasi dan menyediakan laporan.
\end{abstract}

Kata kunci : Sistem Informasi, Ticketing Online, Waterfall, Booking Engine.

\section{Pendahuluan}

\subsection{Latar Belakang}

Perkembangan teknologi dibidang informasi mendorong setiap instansi atau perusahaan untuk seperti PT Pelayaran (penjualan tiket kapal) akan dimudahkan dalam menjalankan bisnisnya dengan internet, karena dalam penyampaian informasi dan pengolahan data penjualan dapat dicapai dengan membangun sebuah web. Web adalah sarana terbaik saat ini dalam penyampaian informasi dan promosi. Dengan adanya web ini diharapkan dapat mengurangi antrian saat calon penumpang membeli tiket kapal diloket.

Tidak jarang juga pelanggan/calon penumpang yang lama mengantri kecewa karena ternyata tiket telah habis terjual. Karena proses penjualan tiket yang masih dilakukan secara manual, pencatatan penjualan/ pemesananan dicatat secara manual dimana seseorang dalam membeli tiket harus datang langsung keloket/ kator penjualan tiket. Hal ini menjadi salah satu alasan antrian, karena saat mendekati hari libur panjang seperti lebaran banyak calon penumpang yang membutuhkan tiket untuk mudik ke kampong halaman. Sehingga penyedia tiket akan kualahan dalam melayani calon penumpang dalam waktu bersamaan. Dan tak jarang hal ini sering dimanfaatkan oleh calo untuk mengambil keuntungan lebih dengan menjual tiket diatas harga standar yang ada karena keterbatasan tiket dan ramainya peminat tiket untuk menyeberang ke pulau Bawean.

Dari permasalahan diatas maka dibangunlah sistem informasi penjualan tiket khususnya pada PT Pelayaran Sakti Inti Makmur penyedia tiket Kapal Express Bahari yang berada di Kota Gresik dengan tujuan Pulau Dengan dibangunnya sistem penjualan tiket secara online ini akan mengurangi antrian calon penumpang saat membeli tiket. Karena calon penumpang yang biasanya membeli tiket langsung ke loket nantinya dapat membeli melalui website sistem yang bisa diakses secara online di komputer pribadi.

Berdasarkan pada latar belakang diatas untuk membangun sistem informasi ini penulis memberi judul sistem: "Rancang Bangun Sistem Informasi Penjualan Tiket Kapal Express Bahari 1C Gresik Bawean Berbasis Web". Sistem ini dibangun agar dalam membooking kursi menjadi lebih mudah, karena dalam melakukan booking calon penumpang bisa memilih kursi kosong yang tersedia.

\subsection{Rumusan Masalah}

a. Bagaimana transaksi penjualan tiket tidak harus selalu datang ke loket.

b. Bagaimana mengatasi agar tidak terjadi antrian yang panjang di loket pada saat 
calon penumpang membeli tiket Kapal Exspress Bahari 1C.

c. Bagaimana agar pihak maskapai lebih mudah dalam mengelola laporan.

\subsection{Batasan Masalah}

a. Aplikasi sistem informasi penjualan tiket ini hanya untuk maskapai Kapal Express Bahari di Gresik.

b. Sistem Informasi ini dibangun menggunakan bahasa pemrograman PHP dan HTML serta menggunakan basis data Mysql.

\subsection{Tujuan Penelitian}

a. Supaya pihak jasa penjual tiket dapat memberikan pelayanan yang baik bagi penumpang dalam membeli tiket.

b. Supaya penjualan tiket lebih tersistem tidak ada kelebihan penumpang dan tiket tidak lagi diperjual belikan oleh calo.

c. Supaya dalam mencatat penjualan tiket lebih mudah karena dari sistem sudah bisa langsung dicetak karena sebelumnya pencatatan masih manual.

\section{Metode}

\subsection{Metodologi Penelitian}

Berikut adalah kerangka konsep yang digunakan oleh penulis

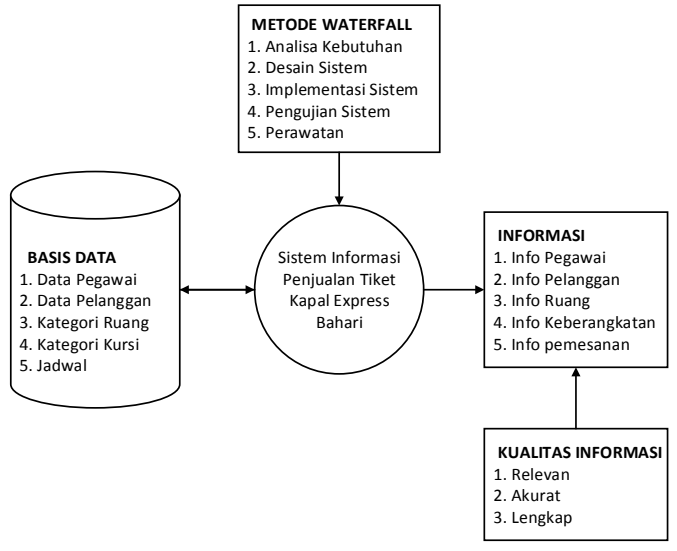

Gambar 2.1 Kerangka Konsep Penelitian

\subsection{Metode Waterfall}

Metode perancangan yang digunakan untuk melakukan penelitian adalah metode waterfall. Metode Wterfall adalah metode yang menyarankan sebuah pendekatan yang sistematis dan skuensial melaui tahapan-tahapan yang ada pada siklus hidup pengembangan system (SDLC) untuk membangun sebuah perangkat lunak. Berikut urutan perancangan waterfall dalam proses pengembangan perangkat lunak :

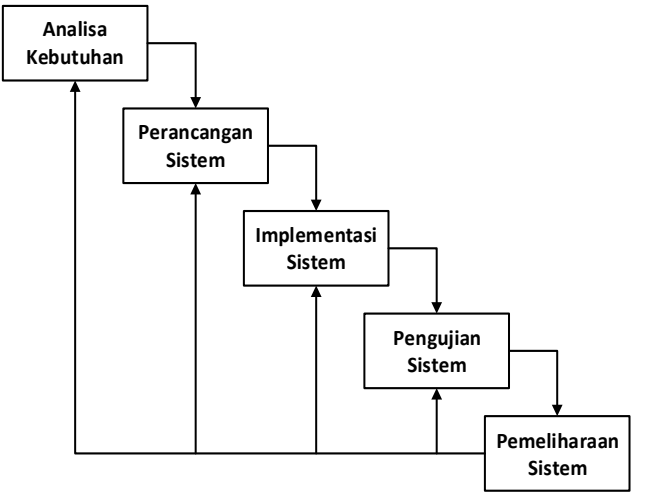

Gambar 2.2 Metode Perancangan Waterfall

a. Analisa Kebutuhan

Pengumpulan data dalam tahap ini melakukan sebuah penelitian, wawancara atau studi literatur.

b. Perancangan Sistem

Menterjemahkan syarat kebutuhan sebuah perancangan perangkat lunak yang dapat diperkirakan sebelum dibuat coding.

c. Implementasi Sistem

Hasil dari perancangan sistem yang diterapkan kedalam user interface menjadi bentuk sitem informasi melalui sebuah coding.

d. Pengujian Sistem

Sistem diuji coba pada user untuk digunakan sebagaimana mestinya untuk menghasilkan sebuah output demi mengetahui kelayakan sistem.

e. Perawatan

Sistem tentu akan ada kekurangan pada saat sudah digunakan, perawatan adalah untuk memperbaiki kekurangan/ kelemahan sistem tersebut.

3. Hasil

3.1 WBS (Work Breakdown Structure)

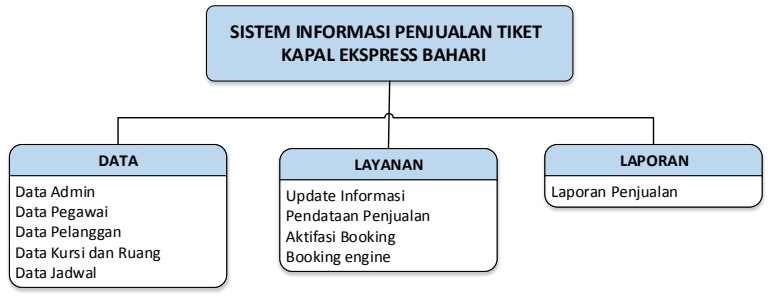

Gambar 3.1 WBS (Work Breakdown Structure) 


\subsection{Use Case}

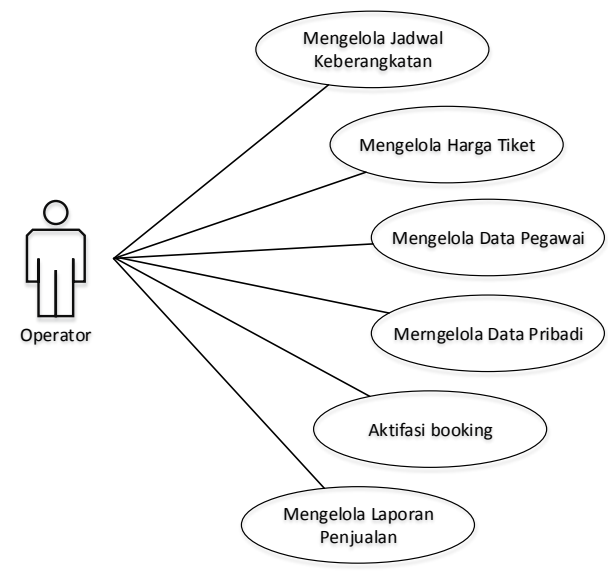

Gambar 3.2 Aktifitas Operator kepada Sistem

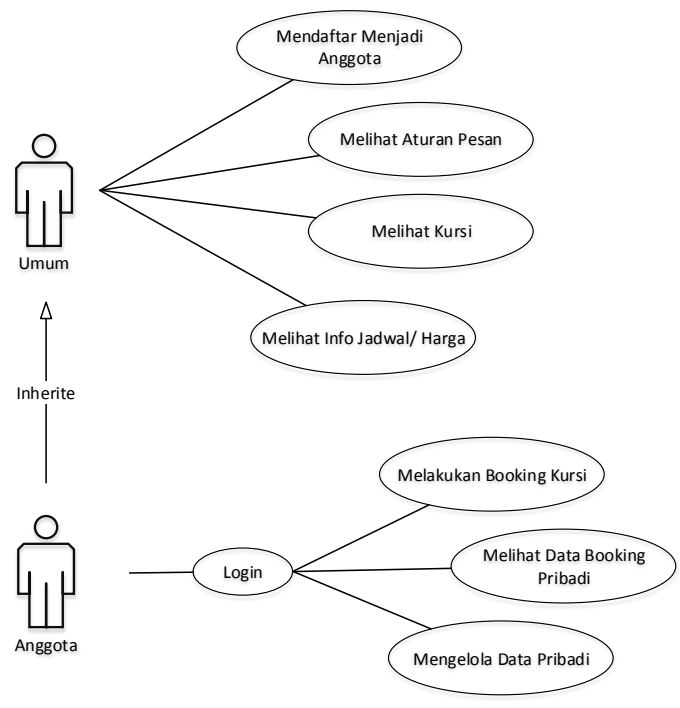

Gambar 3.3 Aktifitas User kepada Sistem

\subsection{Diagram Flow}

Alur dari system pemesanan tiket berbasis web ini dapat digambarkan seperti diagram flow dibawah ini :

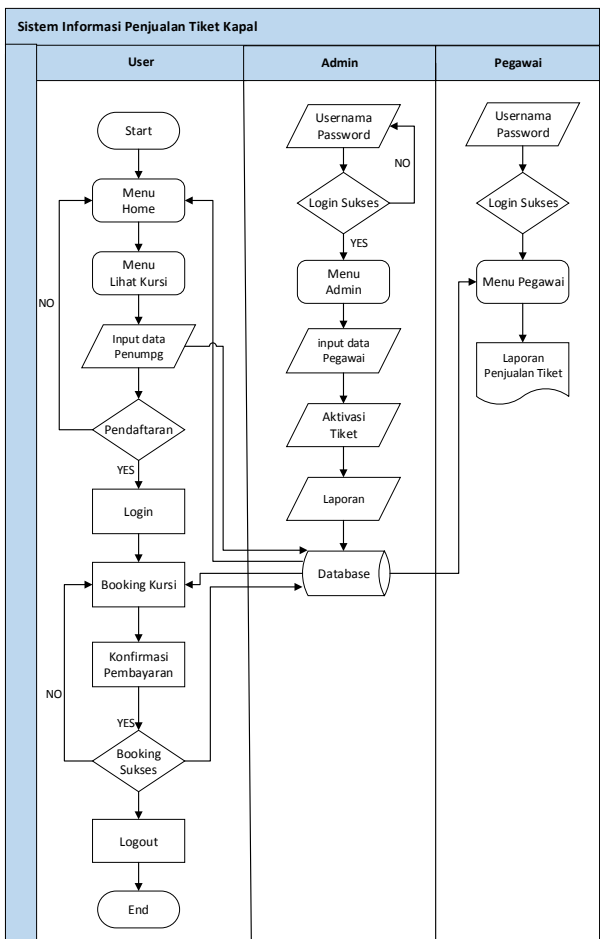

Gambar 3.4 Diagram Flow Sistem Informasi Penjualan Tiket

\subsection{ERD (Entity Relationship Diagram)}

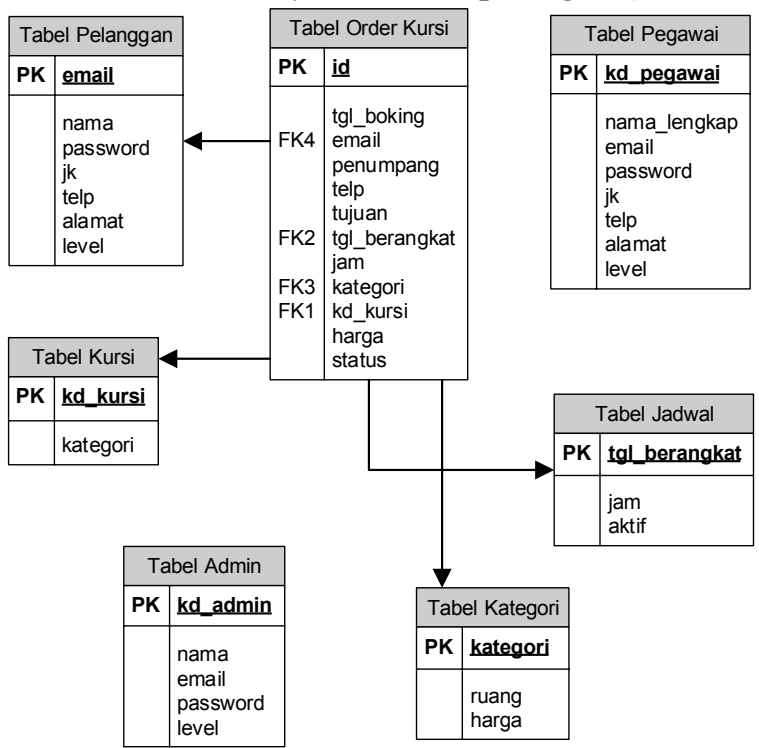

Gambar 3.5 Desain Relasi pada Basis Data 


\section{Pembahasan}

\subsection{Database Sistem}

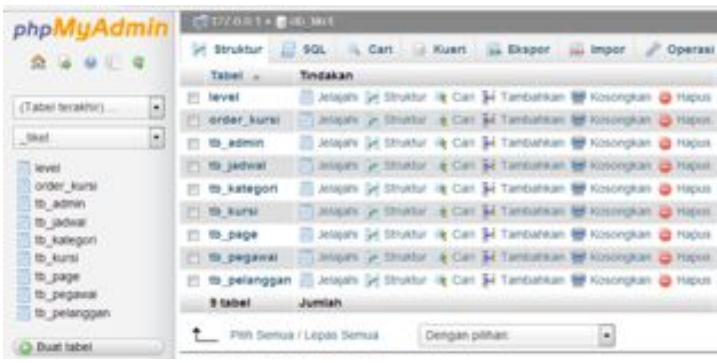

Gambar 4.1 Basis Data Sistem

\subsection{Halaman User}

user terletak pada sidebar website, yang digunakan untuk member login.

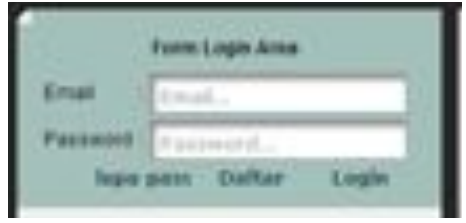

Gambar 4.2 Form Login User

Halaman utama login adalah masuk pada menu home.

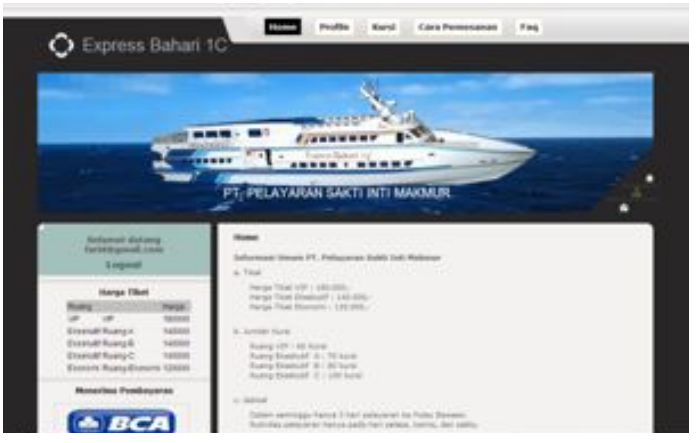

Gambar 4.3 Form Login User

Untuk mulai membeli tiket atau mem-booking kursi masuk pada menu kursi.

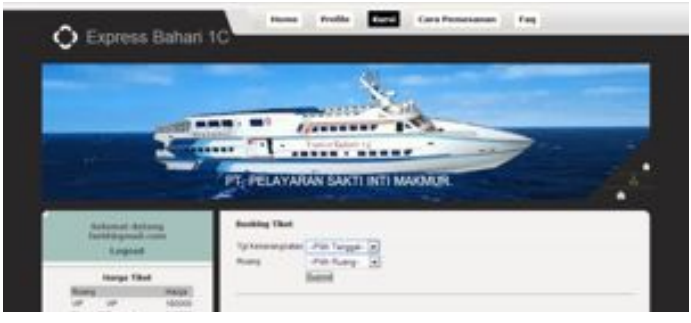

Gambar 4.4 Halaman Booking

\subsection{Halaman Admin}

Pada menu jadwal halaman admin adalah untuk melakukan input tanggal keberangkatan.

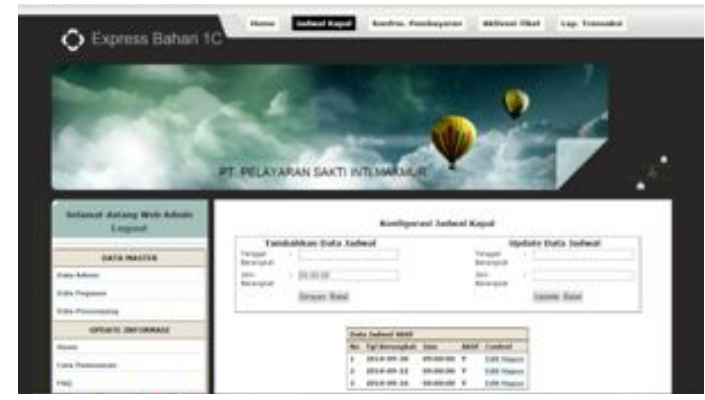

Gambar 4.5 Pengaturan Jadwal Keberangkatan

Setelah member melakukan pembayaran dan melakukan konfirmasi pada sistem, data akan masuk pada menu konfirmasi pembayaran.

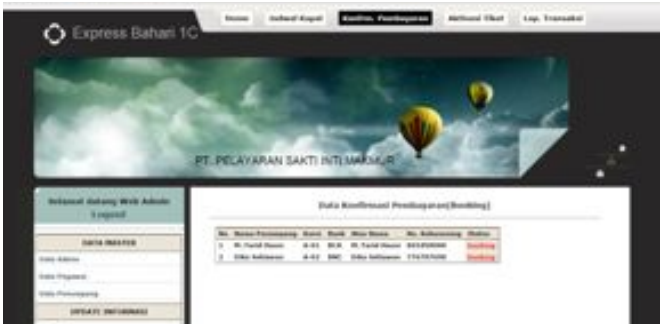

Gambar 4.6 Konfirmasi Pembayaran dan Aktifasi Booking

Data penumpang yang sudah diaktifasi oleh operator dari booking enjadi ter-booking akan masuk pada menu aktifasi tiket.

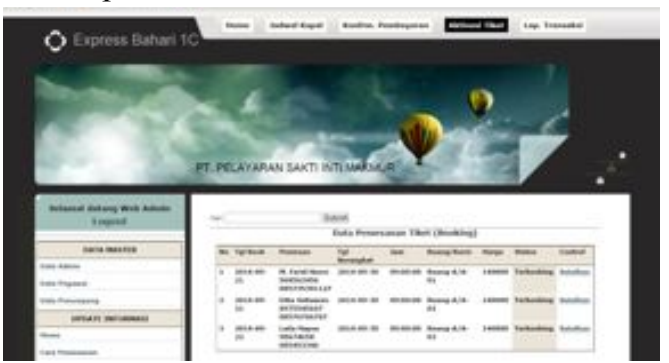

Gambar 5.7 Halaman Booking Penumpang

\subsection{Pengujian}

Pengujian dilakukan dengan login dua user yang berbeda menggunakan dua laptop. Satu laptop sebagai server dan satu laptop lain sebagai client untuk mengakses localhost web. Kemudian keduanya melakukan booking kursi A-05 di ruang A. 


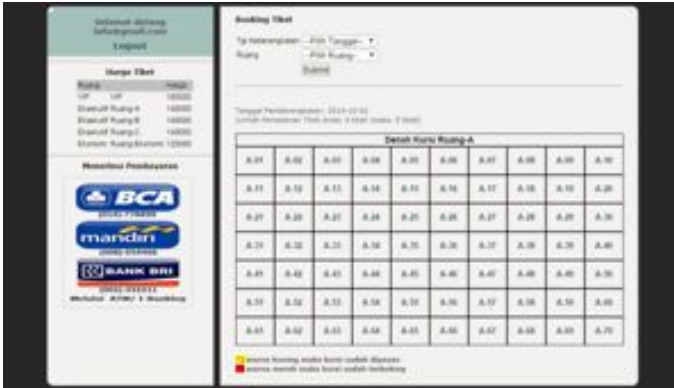

Gambar 4.1 Halaman Memilih Kursi pada User

Halaman User Farid, melakukan pemesanan kursi A-05.

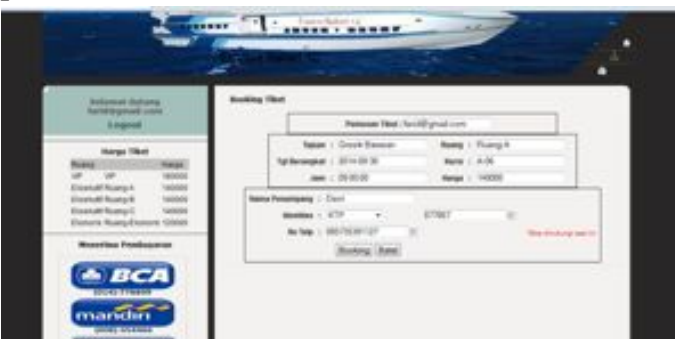

Gambar 4.2 Halaman Pemesanan pada User 1

Halaman User Dika, melakukan pemesanan kursi A-05, Secara bersamaan kedua user menekan tombol booking. Pada sistem otomatis akan menyeleksi user mana yang mendapatkan kursi tersebut.

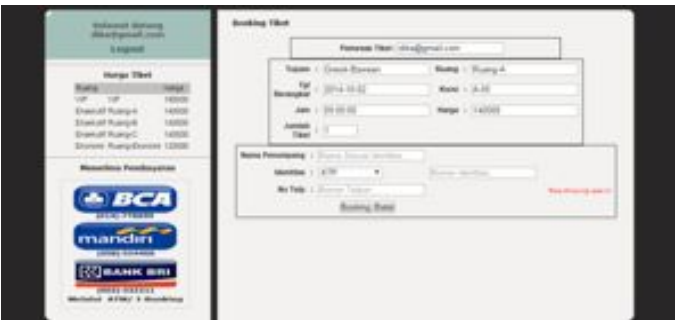

Gambar 4.3 Halaman Pemesanan pada User 2
Salah satu user akan menerima pemberitahuan seperti pada gambar 4.4, bahwa kursi telah terbooking oleh user lain.

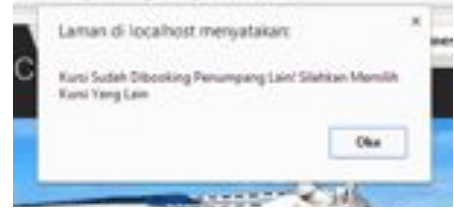

Gambar 4.4 Pemberitahuan

\section{Kesimpulan dan Saran}

\subsection{Kesimpulan}

Berdasar pada hasil perancangan, implementasi, pengujian dan pembahasan terhadap sistem aplikasi yang sudah dibuat, maka diperoleh kesimpulan sebagai berikut :

a. Dengan adanya sistem ini akan lebih memudahkan calon penumpang melakukan pemesanan tiket.

b. Sistem ini akan lebih memudahkan instansi untuk mendata calon penumpang yang akan memesan tiket secara online.

\subsection{Saran}

Pada sistem ini ada beberapa saran yang perlu diberikan, meliputi :

a. Aplikasi sistem yang dibangun bisa dikembangkan menggunakan aplikasi berbasis android.

b. Sistem ini dapat dikembangkan lebih lanjut dengan fitur-fitur yang lebih baik dan inovatif.

Daftar Pustaka

Bunafit Nugroho (2004): APLIKASI

PEMROGRAMAN WEB DINAMDIS

DENGAN PHP DAN MYSQL, GAVA

MEDIA.

Suyanto, Asep, Herman (2009): STEP BY STEP

WEB DESIGN, Andi Yogyakarta.

Khadir, Abdul (2003): PENGENALAN SISTEM

INFORMASI, Yogyakarta:Andi Offset.

Arbie, 2004: Manajemen Database dengan

$M y S Q L$, Andi Yogyakarta.

Anon Kuncoro Widigdo, Dasar Pemrograman

$\begin{array}{ll}P H P & \text { dan } \\ \text { http://www.ilmukomputer.com }\end{array}$

